\title{
Health Disparities Among Exclusively Lesbian, Mostly Lesbian, and Bisexual Young Women
}

\author{
Robin J. Lewis, PhD, ${ }^{1,2}$ Sarah J. Ehlke, MA, Alexander T. Shappie, ${ }^{2}$ \\ Abby L. Braitman, PhD, ${ }^{1,2}$ and Kristin E. Heron, $\mathrm{PhD}^{1,2}$
}

\begin{abstract}
Purpose: Health disparities have been identified between groups of diverse young sexual minority women (SMW) and heterosexual women. This approach may generate sufficient group sizes for statistical analyses but obscures important differences. Moreover, some young women may not identify as "lesbian" or "bisexual" but somewhere in between. This study examined health and sexual minority identity-specific outcomes among three groups of SMW - women who identify as "exclusively lesbian," "mostly lesbian," and "bisexual."

Methods: Participants were 990 young (18-30 years old) SMW (exclusively lesbian: $n=305$, mostly lesbian: $n=133$, bisexual: $n=552$ ) who completed an online survey, including information about mental and physical health symptoms, hazardous drinking, and identity uncertainty. Those who reported alcohol use in the past 30 days responded to questions about their alcohol use and alcohol-related negative consequences.

Results: Controlling for demographic differences, health outcomes varied significantly by identity. Mostly lesbian and bisexual women reported the most depression, anxiety, and physical health symptoms; mostly lesbian women reported the highest levels of hazardous drinking. Among those who reported drinking, mostly lesbian women drank the most frequently and reported the most alcohol-related consequences. Mostly lesbian women reported the most identity uncertainty.

Conclusion: Mostly lesbian women were similar to bisexual women on several health outcomes. They appear unique, however, in drinking behavior and identity uncertainty. Collapsing across identities in health research may affect outcomes.
\end{abstract}

Keywords: alcohol use, bisexual, health disparities, lesbian, mental health, physical health

\section{Introduction}

$\mathbf{T}$ He Institute of Medicine REPORT on lesbian, gay, bisexual, and transgender (LGBT) health documented disparities between sexual minority women (SMW; e.g., lesbian, bisexual) and heterosexual women in behavioral, mental, and physical health outcomes. ${ }^{1}$ Subgroups of SMW are often aggregated to generate sufficient cases for statistical analyses. Although such aggregation may permit examination of differences between SMW and heterosexual women, it may also obscure important differences among subgroups of $\mathrm{SMW}^{2}$ and inadvertently negatively impact statistical power. In particular, aggregating across subgroups when differences exist between them deflates statistical power in two ways. First, effect sizes reflect differences across groups in proportion to the variation within groups, and combining two subgroups falsely inflates the " within- group" variation, resulting in a smaller effect size. Second, if the effects for the subgroups are in opposite directions (such as lesbian women being higher on a construct than heterosexual women, but bisexual women being lower on that same construct), then the effects counter each other and are not detected by statistical analysis. Combining subgroups is often done for the purposes of trying to increase power by having sufficient sample size for each group, but researchers may end up decreasing power if one or both of these issues apply. Moreover, some researchers suggest that classifying sexual identity using traditional labels of heterosexual, lesbian, and bisexual limits participants' ability to describe their identity and they recommend or use a five-option system (heterosexual, mostly heterosexual, lesbian, mostly lesbian, and bisexual) instead. ${ }^{3-5}$ Similarly, others have attempted to be more inclusive in their labeling by considering monosexual identities (e.g., heterosexual and exclusively

\footnotetext{
${ }^{1}$ Department of Psychology, Old Dominion University, Norfolk, Virginia

${ }^{2}$ Virginia Consortium Program in Clinical Psychology, Norfolk, Virginia.
} 
lesbian) and nonmonosexual identities (e.g., mostly lesbian, bisexual, and mostly heterosexual). ${ }^{6}$

The differing classification of sexual identity is critical to consider, as it may contribute to differential findings regarding health behavior outcomes. ${ }^{7}$ Most studies to date have focused on comparisons of SMW (defined broadly) to heterosexual women. Relatively fewer studies have compared subgroups of SMW. To enhance our understanding of SMW's health, and nonmonosexual identities in particular, this study aimed to examine health disparities among identities specific to SMW-women who endorse identities of exclusively lesbian, mostly lesbian, or bisexual. Consideration of these three subgroups permits a more nuanced examination of health outcomes among SMW and in particular illuminates how a mostly lesbian identity is similar to, and different from, an exclusively lesbian or a bisexual identity.

\section{Health disparities in sexual minority and heterosexual women}

SMW are at increased risk for anxiety, depression, and alcohol use disorders (AUDs) compared with heterosexual women. ${ }^{8,9}$ In a nationally representative sample, both lesbian and bisexual identities conferred risk for mood disorders, with bisexual individuals at the greatest risk when compared with heterosexual women. ${ }^{10}$ Similarly, exclusively lesbian, mostly lesbian, and bisexual women were more likely to report past year and lifetime depression compared with heterosexual women. ${ }^{5}$

Examinations of subgroups of SMW have found that bisexual women were more likely to report past year and lifetime depression, ${ }^{5} 12$-month loneliness, hopelessness, sadness, depression, and anxiety, ${ }^{11}$ more frequent mental distress, ${ }^{12}$ and more psychological distress ${ }^{13}$ compared with lesbian women. In contrast, in two other studies no differences were found between lesbian and bisexual women for lifetime and 12-month depression, ${ }^{14,15}$ and anxiety disorders. ${ }^{14}$ In one of the few studies that compared bisexual, mostly lesbian, and exclusively lesbian individuals, bisexual women were more likely to report past year and lifetime depression compared with the other two groups. ${ }^{5}$ Similarly, in another study, bisexual women reported more past week depression symptoms and past year anxiety symptoms than a single combined group of mostly lesbian and exclusively lesbian individuals who did not differ from one another. ${ }^{16}$ However, one of the two studies that included bisexual, mostly lesbian, and exclusively lesbian identities had a very small sample size for the bisexual $(n=16)$ group 5 and the other did not report the size of the mostly lesbian group that was combined with the "only" lesbian group. ${ }^{16}$ Consequently, it is possible that the examinations across groups were underpowered due to the small number of people in some subgroups. It is therefore important to study subgroups of SMW separately in a sample with enough cases for each subgroup to detect any potential differences between them.

Regarding alcohol misuse, population-based research has shown that lesbian and bisexual women are more likely to engage in heavy drinking, $, 17,18$ drinking and driving, ${ }^{9}$ binge drinking, ${ }^{9,19,20}$ high-intensity binge drinking, ${ }^{20}$ and to meet criteria for an AUD $^{9}$ than heterosexual women. Based on national survey data in Australia, bisexual (but not lesbian) women were more likely to report binge drink- ing compared with heterosexual women. ${ }^{21}$ Similarly, results from the National Health Interview Survey revealed that heavy drinking ( $>7$ drinks per week) was more common among lesbian and bisexual women than heterosexual women; however, comparisons between lesbian and bisexual women were not examined. ${ }^{22}$

Among the studies to directly compare subgroups of SMW on alcohol-related outcomes, most, but not all, revealed that bisexual women report greater likelihood of drinking in the past 30 days ${ }^{23}$ hazardous drinking, ${ }^{4,5}$ alcohol consequences, ${ }^{5,23}$ intoxication, ${ }^{5}$ past year dependence symptoms, ${ }^{5,15}$ and binge drinking. ${ }^{12}$ In contrast, select studies have found no differences in hazardous drinking, ${ }^{16}$ binge drinking ${ }^{21}$ or past year AUD between lesbian and bisexual women. ${ }^{24}$ In one of the few studies that examined mostly lesbian women specifically, bisexual women reported more alcohol-related consequences and dependence than mostly lesbian women. ${ }^{5}$ Although SMW engage in more problematic alcohol use compared with heterosexual women, relatively few studies have examined alcohol use outcomes among SMW subgroups, and existing studies provide conflicting findings.

Compared with mental health and alcohol use, relatively less is known about physical health disparities for and among SMW. The IOM report ${ }^{1}$ noted that lesbian and bisexual women are at greater risk of obesity, cardiovascular disease, and some types of cancer, and a systematic review has suggested that SMW report poorer health outcomes compared with heterosexual women. ${ }^{25} \mathrm{~A}$ study of Washington state residents also found that lesbian and bisexual women were at greater risk for poor general health and experiencing physical limitations; bisexual women had greater odds of hypertension and diabetes compared with heterosexual women. ${ }^{17}$ In another study, bisexual women reported more non-HIV-related health problems compared with heterosexual women. ${ }^{26}$ Still others found that heterosexual women were more likely to report thyroid problems relative to lesbian women (including mostly lesbian women). ${ }^{27}$ In the same study, the very small number of bisexual women limited conclusions about bisexual women's health disparities, possibly indicating why few studies compare lesbian and bisexual women directly. One notable exception revealed that bisexual women were more likely to report poor general health compared with lesbian women. ${ }^{12}$ These preliminary differences suggest that potential health disparities among subgroups of SMW merit further examination.

\section{Sexual minority stressors within subgroups of SMW}

Minority stress theory is often used to explain sexual minority health disparities. ${ }^{28,29}$ The unique stressors related to stigmatization and marginalization may account for maladaptive health behaviors and poorer health in SMW compared with heterosexual women. For example, lesbian women reported more discrimination and expectations of discrimination compared with bisexual women. ${ }^{13}$ On the other hand, bisexual women reported more concealment and internalized heterosexism compared with women who identified as gay, lesbian, or queer. ${ }^{13}$ Identity uncertainty, or the degree to which one is uncertain regarding sexual identity (also described as identity confusion) is positively associated with minority stress variables such as internalized homonegativity, 
concealment motivation, and difficulty accepting a sexual minority identity. ${ }^{30,31}$ In several studies, bisexual men and women collectively reported greater identity uncertainty or confusion than their peers who identified as lesbian or gay, ${ }^{32-34}$ but bisexual participants did not report greater identity uncertainty than their gay/lesbian peers in another recent study. ${ }^{31}$ Given the association of identity uncertainty with sexual minority stress and recent discrepant findings between different sexual minority subgroups, examining the degree to which there are differences in identity uncertainty among lesbian, mostly lesbian, and bisexual women may shed some light on health disparities among SMW.

\section{Mostly lesbian identity}

Discrepant findings with regard to health disparities and identity uncertainty for sexual minority individuals may be related to how SMW are classified in terms of sexual identity and the heterogeneity of subgroups of SMW. Researchers have pointed out that SMW are not necessarily a homogeneous group, ${ }^{1,4,10}$ emphasizing the importance of examining groups of lesbian and bisexual women separately. Moreover, heterogeneity may also exist within groups of lesbian- and bisexual-identified women as some SMW identify as a "mostly lesbian" group. ${ }^{3}$ Vrangalova and Savin-Williams argue for the importance of expanding our conceptualization of sexual identity beyond the three traditional categories (i.e., heterosexual, bisexual, and gay/lesbian), pointing out the frequency with which research participants endorse "mostly" categories as well as evidence that these categories represent psychological profiles that are distinct from the three traditional sexual identity categories. ${ }^{3,35}$

Despite calls for a more nuanced approach in categorizing identity groups among SMW when investigating health disparities, a mostly lesbian identity is not consistently assessed and only a handful of studies have examined mostly lesbian women separately from other SMW, as we described previously. ${ }^{4,5}$ In some studies, a mostly lesbian identity was assessed, but it is not clear whether they were aggregated with exclusively lesbian or bisexual women for the analyses. ${ }^{15}$ In other studies, mostly lesbian identified women were combined with exclusively lesbian women for analytic purposes. $^{16,21,27}$ An alternative classification system was proposed in yet another study in which mostly lesbian, bisexual, and mostly heterosexual women were combined into a single nonmonosexual group and compared with a monosexual group (i.e., exclusively lesbian and heterosexual women). ${ }^{6}$ It is evident that there are conflicting approaches to categorizing SMW, and addressing the question of how best to classify women who endorse a mostly lesbian identity in health research is essential to a better understanding of SMW's health.

\section{Current study}

Relatively little is known about similarities and differences in health and identity uncertainty among exclusively lesbian, mostly lesbian, and bisexual women. Mostly lesbian women are seldom examined as a distinct group and findings regarding differences between lesbian and bisexual women are mixed, perhaps due to sampling differences and relatively small samples of bisexual or mostly lesbian women. ${ }^{5}$ With a large sample of young SMW that permits properly powered comparisons of these three groups, the aim of this study was to compare health (depression symptoms, anxiety symptoms, hazardous drinking, and physical symptoms), and identity uncertainty among these three sexual identity groups. These comparisons should enhance our understanding of health disparities among subgroups of SMW. Recognizing the mixed findings in the literature about subgroups of SMW, we made no a priori predictions about how mostly lesbian women would be similar to, and different from, exclusively lesbian and bisexual women.

\section{Methods \\ Participants and procedure}

Participants were 990 SMW who self-identified as cisgender female, and either exclusively lesbian $(n=305)$, mostly lesbian $(n=133)$, or bisexual $(n=552)$ and were $18-30$ years old (mean $[M]=22.64$, standard deviation $[S D]=3.45$ ). Most participants were recruited through Facebook advertisements; a small number were recruited through other online sources and friends. Facebook advertisements were run over the course of 5 days and included advertisements on Facebook as well as Instagram. An identical advertisement was used on both platforms that stated "Study for [Bisexual or Lesbian] women aged 18-30! Chance to win one of several Amazon.com gift cards!" SMW were targeted by their interest in LGBT-related pages and indicating that they were romantically interested in women on their profile.

Basic demographic information was collected (age, race/ethnicity, education, income, and relationship status). After initial online screening, eligible participants provided informed consent and completed a 30-minute online survey of health behaviors and sexual minority experiences. Only participants who reported drinking in the past 30 days ( $n=543,54.8 \%$ ) completed the alcohol use and alcohol consequences questionnaires. At the conclusion of the study, participants were given the option to provide their contact information to be entered into a raffle to win 1 gift card of $\$ 50$ from Amazon.com, 1 of 5 gift cards of \$25 from Amazon.com, or 1 of 10 gift cards of $\$ 10$ from Amazon.com. Data collection occurred in April 2016. All procedures were approved by the Institutional Review Board at Old Dominion University.

\section{Measures}

Sexual identity was operationalized by the question, "Which of the following best describes your sexual identity?" with the following response options: Exclusively lesbian/gay, mostly lesbian/gay, bisexual, mostly heterosexual, exclusively heterosexual, and other.

Depression and anxiety symptoms. The Mental Health

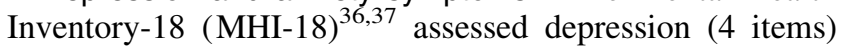
and anxiety (5 items) symptoms in the past 4 weeks. Participants used a 6-point scale from 1 (All of the time) to 6 (None of the time) to indicate how often in the past 4 weeks they have been bothered by each symptom. All items for depression symptoms and four items for anxiety symptoms were reverse scored. The average for each score (depression symptoms and anxiety symptoms) was computed. Next, a standardized score was computed for each subscale by subtracting 
one from the mean score, then multiplying by $20 .^{37,38}$ Thus, scores for depression and anxiety each ranged from 0 to 100 with higher scores indicating more problems. The MHI has demonstrated high convergent validity among general population samples. ${ }^{36}$

Hazardous drinking. The Alcohol Use Disorders Identification Test (AUDIT) ${ }^{39}$ is a 10 -item measure assessing hazardous alcohol use, including alcohol quantity and frequency, signs of alcohol dependence, and alcohol-related problems. A continuous measure of the AUDIT was used for the current study. The AUDIT has shown good validity. ${ }^{40-42}$

Alcohol use. The Daily Drinking Questionnaire (DDQ) ${ }^{43}$ examined alcohol use among those who reported drinking in the past 30 days. Participants reported how many drinks they consumed for each day of a typical week in the past 30 days. Typical weekly alcohol frequency represented the total number of days participants reported consuming at least one standard drink (i.e., number of drinking days). In addition, drinks per drinking day represented the sum of the number of drinks consumed for a typical week divided by typical weekly alcohol frequency. The DDQ is used widely among young adults ${ }^{44,45}$ and $\mathrm{SMW}^{46,47}$ and has shown strong psychometric properties. ${ }^{48-51}$

Alcohol consequences. Participants who reported drinking in the past month completed the Brief Young Adult Alcohol Consequences Questionnaire (B-YAACQ). ${ }^{52}$ Participants responded yes (1) or no (0) to 24 items that examined past 30-day alcohol-related consequences. A total score was computed by summing all affirmative responses. The B-YAACQ has shown good concurrent validity. ${ }^{52}$

Physical health. The Cohen-Hoberman Inventory of Physical Symptoms (CHIPS) ${ }^{53}$ assessed participants' physical health problems in the previous 2 weeks. The scale consists of 33 common physical health problems (e.g., "headache," "back pain"). Participants indicated the extent to which each symptom bothered them during the previous 2 weeks using a 5-point scale ranging from 0 (Not at all bothered) to
4 (Extremely bothered). A total score was calculated by summing the number of physical symptoms reported, with greater scores indicating worse physical health (i.e., greater frequency of physical health problems). The CHIPS has demonstrated strong psychometric properties with college students and self-identified lesbian women. ${ }^{53,54}$

Identity uncertainty. The Identity Uncertainty subscale of the Lesbian, Gay, and Bisexual Identity Scale (LGBIS) ${ }^{55}$ is a 4-item measure that assesses uncertainty about sexual orientation/identity. Items are: "I' $m$ not totally sure what my sexual orientation is," "I get very confused when I try to figure out my sexual orientation," "I keep changing my mind about my sexual orientation," and "I can't decide whether I am bisexual or homosexual". Participants responded to each item using a 6-point scale ranging from 1 (Disagree Strongly) to 6 (Agree Strongly). The mean for the Identity Uncertainty items was computed, with higher scores reflecting more uncertainty. The LGBIS has demonstrated strong test/retest reliability ${ }^{55}$ and construct validity. ${ }^{55}$

\section{Data analyses}

Table 1 displays the Cronbach's alpha reliability estimates for the total sample and each sexual identity group for the continuous measures. First, normality was confirmed for all continuous variables. All analyses were conducted using SPSS 25 (released 2017 by IBM corporation; Armonk, NY). Multiple imputation with a total of 20 imputations was used to account for missing data for outcome variables. Correlation and one-way analysis of variance (ANOVA) tests were conducted between demographic and outcome variables to examine potential demographic covariates (Table 2). Demographic variables that were significantly associated with the outcome variable (Table 2) were included as covariates for that specific analysis. No demographic variables were significantly associated with hazardous drinking and alcohol consequences (Table 2); thus, ANOVA models were conducted. Multiple ANOVA or analysis of covariance (ANCOVA; if covariates were included) tests were conducted with sexual identity (exclusively lesbian, mostly lesbian, or bisexual) as the grouping variable. For significant

Table 1. Cronbach's Alpha Reliability Estimates for the Total Sample and Each Sexual Identity Group for Health Behaviors, the Identity Uncertainty Variable, and Alcohol Consequences

Total sample, $\mathrm{N}=990$ Exclusively lesbian/gay, $\mathrm{n}=305$ Mostly lesbian, $\mathrm{n}=133$ Bisexual, $\mathrm{n}=552$

\begin{tabular}{lcccc}
\cline { 2 - 4 } Variable & $\alpha$ & $\alpha$ & $\alpha$ & $\alpha$ \\
\hline Health behaviors & & & & \\
$\quad$ Anxiety symptoms & 0.85 & 0.86 & 0.86 & 0.84 \\
Depression & 0.90 & 0.89 & 0.91 & 0.90 \\
$\quad$ symptoms & 0.82 & 0.79 & 0.81 & 0.84 \\
$\begin{array}{l}\text { Hazardous drinking } \\
\text { Physical health }\end{array}$ & 0.92 & 0.93 & 0.94 & 0.91 \\
$\begin{array}{l}\text { Symptoms } \\
\text { Identity uncertainty }\end{array}$ & 0.86 & 0.83 & 0.91 & 0.83 \\
\hline Alcohol variables & $\mathrm{n}=543$ & $\mathrm{n}=170$ & $\mathrm{n}=76$ & $\mathrm{n}=297$ \\
\hline Alcohol consequences & 0.87 & 0.88 & 0.86 & 0.87 \\
\hline
\end{tabular}


ANOVAs/ANCOVAs, Tukey's honestly significant difference post hoc tests examined pairwise differences among sexual identity groups. The full sample $(N=990)$ was used in the ANOVAs/ANCOVAs for all variables, except alcohol use (frequency and drinks per day), and alcohol-related consequences, which were conducted only among participants who endorsed drinking in the past 30 days $(n=543)$.

\section{Results}

The sample of SMW was $71.1 \%$ White, $81.5 \%$ had an education of some college or higher, and $50.4 \%$ were in a relationship or married (see Table 3 for demographic characteristics). ANOVA results indicated that exclusively lesbian women were significantly older than mostly lesbian and bisexual women, $F=17.92, p<0.001$, and chi-square analyses indicated differences between sexual identity and relationship status, $\chi^{2}$ $(4)=19.13, p=0.001$, income, $\chi^{2}(10)=32.98, p<0.001$, and recruitment method, $\chi^{2}(4)=33.73, p<0.001$. ANCOVA results revealed significant differences among exclusively lesbian, mostly lesbian, and bisexual women on anxiety symptoms (power $=0.88$ ), depression symptoms (power $=0.96$ ), and physical health symptoms (power $=0.71$; Table 4 ). Mostly lesbian and bisexual women reported more depression, anxiety, and physical health symptoms than exclusively lesbian women.

ANOVA results revealed significant differences in hazardous drinking (power $=0.59$ ). Compared with exclusively lesbian and bisexual women, mostly lesbian women reported the most hazardous drinking. Also shown in Table 4, ANCOVA results showed that among drinkers there were significant differences among exclusively lesbian, mostly lesbian, and bisexual women on alcohol frequency (power $=0.70)$ and drinks per day (power $=0.45$ ). ANOVA results showed differences in alcohol consequences (power $=0.52$ ). Post hoc analyses showed that mostly lesbian women reported more frequent drinking and more alcohol-related consequences than exclusively lesbian and bisexual women, but there were no significant group differences on drinks per day. As shown in Table 4, ANCOVA results showed that all groups were significantly different on identity uncertainty (power $>0.99$ ), where mostly lesbian women reported the highest identity uncertainty, bisexual women reported the second highest, and lesbian women were the lowest.

\section{Discussion}

Although past research has demonstrated significant health disparities between heterosexual and SMW, there are far fewer, and more conflicting, findings regarding differences between subgroups of SMW. The objective of the present study was to compare three subgroups of SMW-exclusively lesbian, mostly lesbian, and bisexual—on health outcomes. Identity uncertainty among the three groups was also examined as it is possible that such uncertainty might explain health disparities. The results suggested that women who identified as mostly lesbian were generally similar to bisexual women in terms of greater mental and physical health problems. Importantly, a somewhat different pattern emerged with the alcohol outcomes as mostly lesbian women reported more hazardous drinking than bisexual or lesbian women. Also, among

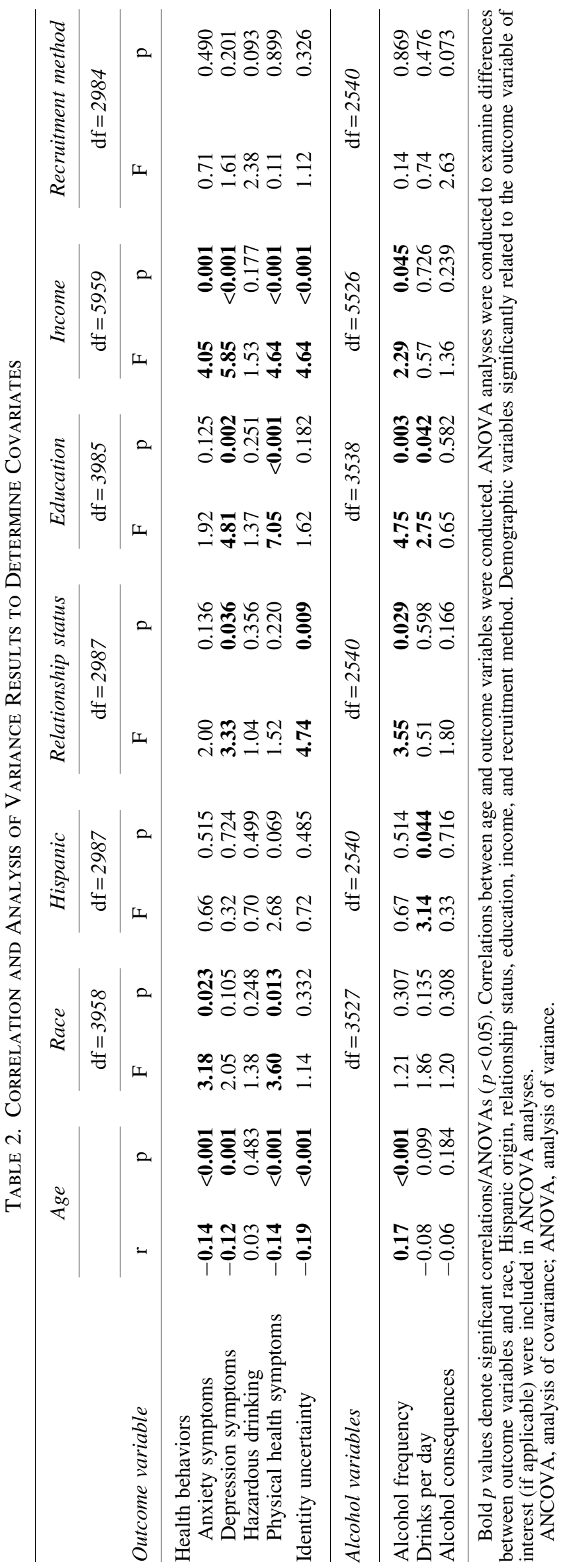


Table 3. Characteristics of the Sample of Sexual Minority Women

\begin{tabular}{|c|c|c|c|c|}
\hline & $\begin{array}{l}\text { Total sample } \\
(\mathrm{N}=990)\end{array}$ & $\begin{array}{c}\text { Exclusively } \\
\text { lesbian/gay }(\mathrm{n}=305)\end{array}$ & $\begin{array}{l}\text { Mostly lesbian } \\
\quad(\mathrm{n}=133)\end{array}$ & $\begin{array}{l}\text { Bisexual } \\
(\mathrm{n}=552)\end{array}$ \\
\hline Age, ${ }^{\mathrm{a}} \mathrm{M}(\mathrm{SD})$ & $22.64(3.45)$ & $23.61(3.70)$ & $22.53(3.46)$ & $22.14(3.20)$ \\
\hline \multicolumn{5}{|l|}{ Race, ${ }^{\mathrm{a}} n(\%)$} \\
\hline White & $684(71.1)$ & $207(69.7)$ & $98(75.4)$ & $379(70.9)$ \\
\hline Black & $148(15.4)$ & $47(15.8)$ & $20(15.4)$ & $81(15.1)$ \\
\hline Other & $83(8.6)$ & $30(10.1)$ & $5(3.8)$ & $48(9.0)$ \\
\hline Multiracial & $47(4.9)$ & $13(4.4)$ & $7(5.4)$ & $27(5.0)$ \\
\hline Hispanic (yes), ${ }^{\mathrm{a}} n(\%)$ & $168(17.0)$ & $57(18.7)$ & $19(14.3)$ & $92(16.7)$ \\
\hline \multicolumn{5}{|l|}{ Relationship status, $n(\%)$} \\
\hline Single & $457(46.2)$ & $115(37.7)$ & $62(46.6)$ & $280(50.7)$ \\
\hline In a relationship/married & $499(50.4)$ & $182(59.7)$ & 69 (51.9) & $248(44.9)$ \\
\hline Other & $34(3.4)$ & $8(2.6)$ & $2(1.5)$ & $24(4.3)$ \\
\hline \multicolumn{5}{|l|}{ Education, ${ }^{\text {a }} n(\%)$} \\
\hline High school diploma or less & $183(18.5)$ & $56(18.4)$ & $17(12.8)$ & $110(19.9)$ \\
\hline Some college & $549(55.5)$ & $157(51.6)$ & $79(59.4)$ & $313(56.7)$ \\
\hline Bachelor's degree & 197 (19.9) & $64(21.1)$ & $28(21.0)$ & $105(19.0)$ \\
\hline Graduate degree & $60(6.1)$ & $27(8.9)$ & $9(6.8)$ & $24(4.4)$ \\
\hline \multicolumn{5}{|l|}{ Individual income, ${ }^{\mathrm{a}} n(\%)$} \\
\hline$\$ 0$ (no income) & $185(19.2)$ & $43(14.5)$ & $26(20.2)$ & $116(21.5)$ \\
\hline$\$ 1-\$ 9,999$ & $265(27.5)$ & $64(21.6)$ & $37(28.7)$ & $164(30.3)$ \\
\hline$\$ 10,000-\$ 19,999$ & $204(21.1)$ & $65(22.0)$ & $25(19.4)$ & $114(21.1)$ \\
\hline$\$ 20,000-\$ 29,999$ & $143(14.8)$ & $45(15.2)$ & $22(17.0)$ & $76(14.1)$ \\
\hline$\$ 30,000-\$ 39,999$ & $87(9.0)$ & $39(13.2)$ & $10(7.7)$ & $38(7.0)$ \\
\hline$\$ 40,000$ or higher & $81(8.4)$ & $40(13.5)$ & $9(7.0)$ & $32(6.0)$ \\
\hline \multicolumn{5}{|l|}{ Recruitment, ${ }^{\mathrm{a}} n(\%)$} \\
\hline Facebook & $869(88.1)$ & $253(83.2)$ & $112(84.2)$ & $504(91.6)$ \\
\hline Friend/referral & $18(1.8)$ & $2(0.7)$ & $8(6.0)$ & $8(1.5)$ \\
\hline Other & $100(10.1)$ & $49(16.1)$ & $13(9.8)$ & $38(6.9)$ \\
\hline
\end{tabular}

${ }^{a}$ Missing data, sample values may not equal column totals. Percentages do not include missing data and total $100 \%$.

$\mathrm{M}$, mean; SD, standard deviation.

drinkers, mostly lesbian women drank more frequently and reported more alcohol-related consequences compared with both exclusively lesbian and bisexual women. Regarding identity uncertainty, those with a mostly lesbian identity endorsed more identity uncertainty than bisexual women who endorsed more identity uncertainty than those with an exclusively lesbian identity.

In general, our findings are consistent with previous literature suggesting that bisexual women experience more physical $^{12}$ and mental health problems ${ }^{5,11-13}$ and maladaptive alcohol use $e^{4,5,15,23}$ compared with lesbian women. Unlike previous research, in which mostly lesbian women were similar to lesbian women regarding depression and alcohol misuse, ${ }^{5,16}$ our results suggest that mostly lesbian women are more similar to bisexual women than lesbian women, and sometimes have a uniquely elevated risk compared with both groups. These discrepant findings may be related to demographic differences. Other research examining mostly lesbian women draws from a more racially and ethnically diverse sample spanning ages $21-70$ years ${ }^{5,16}$ compared with our young sample. Recent research suggests that substance use disparities vary across the lifespan. ${ }^{2}$

These findings are especially interesting given that in previous literature mostly lesbian women are typically grouped with exclusively lesbian women, ${ }^{16,21,27}$ although they are sometimes grouped with bisexual women. ${ }^{6}$ Moving forward, with sufficient sample sizes, the best strategy would be to ex- amine women who identify as mostly lesbian as a distinct group and if aggregation is necessary, make informed decisions about combining identity groups, potentially based on the outcome of interest. At a minimum, a thorough assessment of identity is necessary as our results suggest that there are important differences within SMW subgroups. Our results suggest that, for young SMW, if collapsing across identities is necessary, mostly lesbian women may fit better with those who identify as bisexual for most health outcomes. Importantly, for alcohol-related outcomes, grouping mostly lesbian women with any other identity seems inappropriate, as mostly lesbian women reported the most hazardous drinking, drank more frequently, and reported more alcoholrelated consequences than either bisexual or exclusively lesbian women.

Once differences in health outcomes for subgroups of SMW are identified, the next logical step is to investigate why these occur. One commonly offered explanation focuses on minority stressors. ${ }^{28,29}$ Identity uncertainty may serve as a type of minority stressor-and mostly lesbian women reported the most uncertainty. We recognize that both distal (e.g., discrimination, harassment, rejection) and proximal stressors (e.g., internalized heterosexism, concealment) need to be assessed in future research within subgroups of SMW. Previous research which has documented that bisexual individuals experience more stress related to concealment and internalized heterosexism may 
Table 4. Analysis of Variance and Analysis of Covariance Results and Means for Health Outcomes AND IDENTITY UNCERTAINTY

\begin{tabular}{|c|c|c|c|c|c|c|c|c|}
\hline \multirow[b]{2}{*}{ Variable } & \multicolumn{5}{|l|}{$\begin{array}{l}\text { Total sample } \\
\mathrm{N}=990\end{array}$} & \multirow{2}{*}{$\begin{array}{c}\text { Exclusively } \\
\text { lesbian/gay, } \mathrm{n}=305 \\
M(S E)\end{array}$} & \multirow{2}{*}{$\begin{array}{c}\begin{array}{c}\text { Mostly lesbian, } \\
\mathrm{n}=133\end{array} \\
M(S E)\end{array}$} & \multirow{2}{*}{$\begin{array}{c}\text { Bisexual, } \\
\mathrm{n}=552\end{array}$} \\
\hline & $M(S E)$ & $\mathrm{df}$ & $\mathrm{F}$ & $\mathrm{p}$ & $\eta_{\text {partial }}^{2}$ & & & \\
\hline \multicolumn{9}{|l|}{ Health behaviors } \\
\hline Anxiety sympto & $57.28(0.93)$ & 2898 & 6.58 & 0.001 & 0.014 & $53.10(1.55)^{\mathrm{a}}$ & $59.19(2.33)^{\mathrm{b}}$ & $59.09(1.28)^{\mathrm{b}}$ \\
\hline $\begin{array}{l}\text { Depression } \\
\text { symptoms }\end{array}$ & 47. & 2922 & & $<\mathbf{0 . 0 0 1}$ & & 12 & & 50 \\
\hline Hazards & & 298 & 3.41 & 0.0 & 0.0 & 4.81 & 6.06 & 5.0 \\
\hline $\begin{array}{l}\text { Physical health } \\
\text { symptoms }\end{array}$ & 37.3 & 292 & 3.93 & 0.020 & 0.009 & 34 & & $1.03)^{b}$ \\
\hline Identity uncertainty & $1.97(0.04)$ & 2924 & 32.21 & $<\mathbf{0 . 0 0 1}$ & 0.065 & $1.62(0.07)^{\mathrm{a}}$ & $2.50(0.10)^{\mathrm{b}}$ & $2.04(0.05)^{\mathrm{c}}$ \\
\hline Alcohol variables & $\mathrm{n}=543$ & & & & & $\mathrm{n}=170$ & $\mathrm{n}=76$ & $\mathrm{n}=297$ \\
\hline & & 25 & & & & & 2. & 2. \\
\hline & & 25 & 3. & & & & & $0.10)^{\mathrm{a}}$ \\
\hline Alcohol consequences & $3.64(0.19)$ & 2540 & 3.36 & 0.036 & 0.012 & $3.18(0.32)^{\mathrm{a}}$ & $4.37(0.53)^{b}$ & $3.38(0.25)^{\mathrm{a}}$ \\
\hline
\end{tabular}

Bold $p$ values denote significant overall ANOVAs/ANCOVAs $(p<0.05)$. ANOVA analyses were conducted for hazardous drinking and alcohol consequences. ANCOVA analyses were conducted for all other variables. Adjusted mean and standard errors are presented for ANCOVA analyses. Higher values for health behaviors indicate greater problems. Higher identity uncertainty values indicate greater identity uncertainty. Higher alcohol values indicate greater alcohol frequency, drinks per day, and alcohol consequences. Groups with different superscripts $(\mathrm{a}, \mathrm{b}$, and/or $\mathrm{c}$ ) indicate significant differences as determined by Tukey's honestly significant difference post hoc tests, $p<0.05$. Groups with the same superscript are not significantly different from each other.

$\mathrm{SE}$, standard error.

explain some disparities. ${ }^{13}$ On the other hand, lesbian women report more discrimination and expectations of discrimination which may also explain some disparities. ${ }^{13}$ Where mostly lesbian women fit in regarding experiences of minority stress remains to be seen and is an important area for future research.

In addition to understanding minority stressors among mostly lesbian women, future research will benefit from qualitative interviews to better understand what factors into their choice of identity when asked. Previous research has suggested that SMW respond differently to questions about sexual identity when provided with five versus three identity options, ${ }^{7}$ but qualitative research exploring these differing responses is lacking.

The labels that young women use to define their sexual orientation and identity have also changed considerably in recent years. It remains to be seen how labels that appear to have increased in recent years (e.g., queer, pansexual) impact what option is chosen when participants are limited to choosing lesbian vs. bisexual. Furthermore, existing labels such as lesbian, mostly lesbian, and bisexual may have different meanings to different individuals, particularly among different age groups. We assessed identity (i.e., "Which of the following best describes your sexual identity?") but it is possible that this identity does not fully encapsulate a participant's sexual attraction and behavior. Finally, it is unclear where individuals who identify as "queer" or "pansexual" may fit in the investigation of health disparities. Some limited previous research has suggested that when queer identified women were compared with both lesbian and bisexual women, queer women were similar to bisexual women in terms of psychological distress but similar to lesbian women in terms of sexual minority stressors of victimization and discrimination, ${ }^{13}$ but more work that considers additional identity labels is needed.

\section{Limitations}

Several limitations should be noted. First, all participants self-identified as lesbian, mostly lesbian, or bisexual. Future research should examine other nonmonosexual identities (e.g., pansexual, queer, mostly heterosexual). If a 5-category model of sexual identity is used, women identifying as mostly heterosexual can also be considered under the broad SMW umbrella. An emerging body of literature ${ }^{4,56}$ has also documented health disparities for mostly heterosexual women. Second, it is unknown how results may generalize to noncisgender women (e.g., nonbinary or transgender women) or sexual minority men. In addition, the current sample consisted of young adults recruited online, who were mostly White and fairly well educated, so generalizations should be made with caution. In particular, our results may differ from previous research due to the limited age range, sample size, and/or method of recruitment. Finally, specific physical health problems (e.g., headaches) were not examined due to low endorsement.

\section{Conclusion}

Describing and classifying SMW is a complex endeavor, and collapsing across identities may mask important differences among these subgroups. Although the common conceptualization of sexual identity includes mostly lesbian women under the bi+ umbrella, there may be important factors that lead women to adopt this sexual identity that sets them apart from their bisexual peers. The present research suggests that women who identify as mostly lesbian may be unique from their exclusively lesbian and bisexual peers by reporting greater identity uncertainty and more hazardous drinking. Moreover, if trying to subsume them within lesbian or bisexual identities, they fall into different patterns for 
different outcomes. Further research is needed to improve our understanding of the development of nonmonosexual identities, and researchers should be mindful that operationalization of sexual identity may affect outcomes.

\section{Disclaimer}

The content of this article is solely the responsibility of the authors and does not represent the official views of the National Institutes of Health, the funding agency. Portions of this research were presented at the American Psychological Association Annual Meeting, San Francisco, CA, August 9-12, 2018 and at the Society of Behavioral Medicine Annual Meeting, Washington, DC, March 6-9, 2019.

\section{Author Disclosure Statement}

No competing financial interests exist.

\section{Funding Information}

Research reported in this article was supported by the National Institute on Alcohol Abuse and Alcoholism of the National Institutes of Health under award number R15AA020424 to Robin Lewis (Principal Investigator). Abby Braitman is supported by K01AA023849.

\section{References}

1. Institute of Medicine (US) Committee on Lesbian, Gay, Bisexual, and Transgender Health Issues and Research Gaps and Opportunities: The Health of Lesbian, Gay, Bisexual, and Transgender People: Building a Foundation for Better Understanding. Washington, DC: The National Academies Press, 2011.

2. Schuler MS, Rice CE, Evans-Polce RJ, Collins RL: Disparities in substance use behaviors and disorders among adult sexual minorities by age, gender, and sexual identity. Drug Alcohol Depend 2018;189:139-146.

3. Vrangalova Z, Savin-Williams RC: Mostly heterosexual and mostly gay/lesbian: Evidence for new sexual orientation identities. Arch Sex Behav 2012;41:85-101.

4. Hughes TL, Szalacha LA, Johnson TP, et al.: Sexual victimization and hazardous drinking among heterosexual and sexual minority women. Addict Behav 2010;35:1152-1156.

5. Wilsnack SC, Hughes TL, Johnson TP, et al.: Drinking and drinking-related problems among heterosexual and sexual minority women. J Stud Alcohol Drugs 2008;69:129-139.

6. Persson TJ, Pfaus JG, Ryder AG: Explaining mental health disparities for non-monosexual women: Abuse history and risky sex, or the burdens of non-disclosure? Soc Sci Med 2015;128:366-373.

7. McCabe SE, Hughes TL, Bostwick W, et al.: Measurement of sexual identity in surveys: Implications for substance abuse research. Arch Sex Behav 2012;41:649-657.

8. King M, Semlyen J, Tai SS, et al.: A systematic review of mental disorder, suicide, and deliberate self harm in lesbian, gay and bisexual people. BMC Psychiatry 2008;8:70.

9. Medley G, Lipari RN, Bose J, et al.: Sexual orientation and estimates of adult substance use and mental health: Results from the 2015 National Survey on Drug Use and Health. 2016. Available at www.samhsa.gov/data/sites/default/files/NSDUHSexualOrientation-2015/NSDUH-SexualOrientation-2015/ NSDUH-SexualOrientation-2015.htm Accessed March 1, 2019.
10. Bostwick WB, Boyd CJ, Hughes T, McCabe SE: Dimensions of sexual orientation and the prevalence of mood and anxiety disorders in the United States. Am J Public Health 2010;100:468-475.

11. Kerr DL, Santurri L, Peters P: A comparison of lesbian, bisexual, and heterosexual college undergraduate women on selected mental health issues. J Am Coll Health 2013;61: 185-194.

12. Fredriksen-Goldsen KI, Kim HJ, Barkan SE, et al.: Disparities in health-related quality of life: A comparison of lesbians and bisexual women. Am J Public Health 2010;100: 2255-2261.

13. Puckett JA, Surace, FI, Levitt HM, Horne SG: Sexual orientation identity in relation to minority stress and mental health in sexual minority women. LGBT Health 2016;3: 350-356.

14. Kerridge BT, Pickering RP, Saha TD, et al.: Prevalence, sociodemographic correlates and DSM-5 substance use disorders and other psychiatric disorders among sexual minorities in the United States. Drug Alcohol Depend 2017;170: 82-92.

15. Jeong YM, Veldhuis CB, Aranda F, Hughes TL: Racial/ethnic differences in unmet needs for mental health and substance use treatment in a community-based sample of sexual minority women. J Clin Nurs 2016;25:3557-3569.

16. Bostwick WB, Hughes TL, Everett B: Health behavior, status, and outcomes among a community-based sample of lesbian and bisexual women. LGBT Health 2015;2:121-126.

17. Dilley JA, Simmons KW, Boysun MJ, et al.: Demonstrating the importance and feasibility of including sexual orientation in public health surveys: Health disparities in the Pacific Northwest. Am J Public Health 2010;100:460-467.

18. Jackson CL, Agénor M, Johnson DA, et al.: Sexual orientation identity disparities in health behaviors, outcomes, and services use among men and women in the United States: A cross-sectional study. BMC Public Health 2016;16:807.

19. Blosnich JR, Farmer GW, Lee JG, et al.: Health inequalities among sexual minority adults: Evidence from ten U.S. states, 2010. Am J Prev Med 2014;46:337-349.

20. Fish JN, Hughes TL, Russell ST: Sexual identity differences in high-intensity binge drinking: Findings from a US national sample. Addiction 2018;113:749-758.

21. Hughes T, Szalacha LA, McNair R: Substance abuse and mental health disparities: Comparisons across sexual identity groups in a national sample of young Australian women. Soc Sci Med 2010;71:824-831.

22. Gonzales G, Przedworski J, Henning-Smith C: Comparison of health and health risk factors between lesbian, gay, and bisexual adults and heterosexual adults in the United States: Results from the National Health Interview Survey. JAMA Intern Med 2016;176:1344-1351.

23. Kerr DL, Ding K, Chaya J: Substance use of lesbian, gay, bisexual and heterosexual college students. Am J Health Behav 2014;38:951-962.

24. Hughes T, McCabe SE Wilsnack SC, et al.: Victimization and substance use disorders in a national sample of heterosexual and sexual minority women and men. Addiction 2010;105:2130-2140.

25. Simoni JM, Smith L, Oost KM, et al.: Disparities in physical health conditions among lesbian and bisexual women: A systematic review of population-based studies. J Homosex 2017;64:32-44.

26. Cochran SD, Mays VM: Physical health complaints among lesbians, gay men, and bisexual and homosexually experienced 
heterosexual individuals: Results from the California Quality of Life Survey. Am J Public Health 2007;97:2048-2055.

27. Andersen JP, Hughes TL, Zou C, Wilsnack SC: Lifetime victimization and physical health outcomes among lesbian and heterosexual women. PLoS One 2014;9:e101939.

28. Hatzenbuehler ML: How does sexual minority stigma "get under the skin"? A psychological mediation framework. Psychol Bull 2009;15:707-730.

29. Meyer IH: Prejudice, social stress, and mental health in lesbian, gay, and bisexual populations: Conceptual issues and research evidence. Psychol Bull 2003;129:674-697.

30. Balsam KF, Mohr JJ: Adaptation to sexual orientation stigma: A comparison of bisexual and lesbian/gay adults. J Couns Psychol 2007;54:306-319.

31. Cramer RJ, Burks AC, Golom FD, et al.: The Lesbian, Gay, and Bisexual Identity Scale: Factor analytic evidence and associations with health and well-being. Meas Eval Couns Dev 2017;50:71-88.

32. de Oliveira JM, Lopes D, Costa CG, Nogueira C: Lesbian, Gay, and Bisexual Identity Scale (LGBIS): Construct validation, sensitivity analyses and other psychometric properties. Span J Psychol 2012;15:334-347.

33. Sarno E, Wright AJ: Homonegative microaggressions and identity in bisexual men and women. J Bisex 2013;13: 63-81.

34. Cramer RJ, Golom FD, Gemberling TM, et al.: Examining the Lesbian, Gay, and Bisexual Identity Scale among members of an alternative sexuality special interest group. Arch Sex Behav 2018;47:1251-1264.

35. Thompson EM, Morgan EM: "Mostly straight" young women: Variations in sexual behavior and identity development. Dev Psychol 2008;44:15-21.

36. Veit CT, Ware JE Jr.: The structure of psychological distress and well-being in general populations. J Consult Clin Psychol 1983;51:730-742.

37. Weinstein MC, Berwick DM, Goldman PA, et al.: A comparison of three psychiatric screening tests using receiver operating characteristic (ROC) analysis. Med Care 1989; 27:593-607.

38. Cokley K, McClain S, Enciso A, Martinez M: An examination of the impact of minority status stress and imposter feelings on the mental health of diverse ethnic minority college students. J Multicult Couns Devel 2013;41:82-95.

39. Babor TF, Higgins-Biddle JC, Saunders JB, Monteiro MG: AUDIT: The Alcohol Use Disorders Identification Test: Guidelines for Use in Primary Care, 2nd ed. Geneva, Switzerland: World Health Organization, 2001.

40. Hays RD, Merz JF, Nicholas R: Response burden, reliability, and validity of the CAGE, Short MAST, and AUDIT alcohol screening measures. Behav Res Methods Instrum Comput 1995;27:277-280.

41. de Meneses-Gaya C, Zuardi AW, Loureiro SR, Crippa JA: Alcohol use disorders identification test (AUDIT): An updated systematic review of psychometric properties. Psychol Neurosci 2009;2:83-97.

42. Reinert DF, Allen JP: The alcohol use disorders identification test: An update of research findings. Alcohol Clin Exp Res 2007;31:185-199.

43. Collins RL, Parks GA, Marlatt GA: Social determinants of alcohol consumption: The effects of social interaction and model status on the self-administration of alcohol. J Consult Clin Psychol 1985;53:189-200.

44. Neighbors C, Dillard AJ, Lewis MA, et al.: Normative misperceptions and temporal precedence of perceived norms and drinking. J Stud Alcohol 2006;67:290-299.

45. Marlatt GA, Baer JS, Kivlahan DR, et al.: Screening and brief intervention for high-risk college student drinkers: Results from a 2-year follow-up assessment. J Consult Clin Psychol 1998;66:604-615.

46. Rhew IC, Stappenbeck CA, Bedard-Gilligan M, et al.: Effects of sexual assault on alcohol use and consequences among young adult sexual minority women. J Consult Clin Psychol 2017;85:424-433.

47. Wilson SM, Gilmore AK, Rhew IC, et al.: Minority stress is longitudinally associated with alcohol-related problems among sexual minority women. Addict Behav 2016;61: 80-83.

48. Litt DM, Lewis MA, Rhew IC, et al.: Reciprocal relationships over time between descriptive norms and alcohol use in young adult sexual minority women. Psychol Addict Behav 2015;29:885-893.

49. Monks SM, Romaka J, Palacios R, Thompson SE: Sexual victimization in female and male college students: Examining the roles of alcohol use, alcohol expectancies, and sexual sensation seeking. Subst Use Misuse 2010;45:2258-2280.

50. Lewis RJ, Mason TB, Winstead BA, Kelley ML: Empirical investigation of a model of sexual minority specific and general risk factors for intimate partner violence among lesbian women. Psychol Violence 2017;7:110-119.

51. Parks KA, Hsieh YP, Collins RL, et al.: Predictors of risky sexual behavior with new and regular partners in a sample of women bar drinkers. J Stud Alcohol Drugs 2009;70:197-205.

52. Kahler CW, Hustad J, Barnett NP: Validation of the 30-day version of the Brief Young Adult Alcohol Consequences Questionnaire for use in longitudinal studies. J Stud Alcohol Drugs 2008;69:611-615.

53. Cohen S, Hoberman HM: Positive events and social supports as buffers of life change stress. J Appl Soc Psychol 1983;13:99-125.

54. Lewis RJ, Derlega VJ, Clarke EG, Kuang JC: Stigma consciousness, social constraints, and lesbian well-being. J Couns Psychol 2006;53:48-56.

55. Mohr JJ, Kendra MS: Revision and extension of a multidimensional measure of sexual minority identity: The Lesbian, Gay, and Bisexual identity Scale. J Couns Psychol 2011;58:234-245.

56. Talley AE, Grimaldo G, Wilsnack SC, et al.: Childhood victimization, internalizing symptoms, and substance use among women who identify as mostly heterosexual. LGBT Health 2016;3:266-274.
Address correspondence to: Robin J. Lewis, PhD Department of Psychology $M G B 250$ Old Dominion University Norfolk, VA 23529-0267

E-mail: rlewis@odu.edu 